\title{
Room Temperature Ferromagnetism of (Mn,Fe) Codoped ZnO Nanowires Synthesized by Chemical Vapor Deposition
}

\author{
Yongqin Chang, ${ }^{1}$ Pengwei Wang, ${ }^{2}$ Qingling Sun, ${ }^{1}$ Yongwei Wang, ${ }^{1}$ and Yi Long1 \\ ${ }^{1}$ School of Materials Science and Engineering, University of Science and Technology Beijing, Beijing 100083, China \\ ${ }^{2}$ Department of Physics, National Key Laboratory of Mesoscopic Physics, Peking University, Beijing 100871, China
}

Correspondence should be addressed to Yongqin Chang, chang@ustb.edu.cn

Received 28 March 2011; Accepted 28 August 2011

Academic Editor: Steve Acquah

Copyright ( 2011 Yongqin Chang et al. This is an open access article distributed under the Creative Commons Attribution License, which permits unrestricted use, distribution, and reproduction in any medium, provided the original work is properly cited.

\begin{abstract}
( $\mathrm{Mn}, \mathrm{Fe})$ codoped $\mathrm{ZnO}$ nanowires were synthesized on silicon substrates in situ using a chemical vapor deposition method. The structure and property of the products were investigated by X-ray, electron microscopy, Raman, photoluminescence, and superconducting quantum interference device magnetometer. The doped nanowires are of pure wurtzite phase with single crystalline, and the elements distribute homogeneously in the doped nanowires. Photoluminescence spectrum of the doped nanowires is dominated by a deep-level emission with a negligible near-band-edge emission. The magnetic hysteresis curve with a coercive field of 35 Oe is clearly observed at $300 \mathrm{~K}$, resulting from room-temperature ferromagnetic ordering in the (Mn,Fe) codoped $\mathrm{ZnO}$ nanowires, which has great potential applications for spintronics devices.
\end{abstract}

\section{Introduction}

Diluted magnetic semiconductors (DMSs) have stimulated great interest in recent years due to their potential applications in spintronics devices, where the spin degree of freedom of the electron is utilized in addition to its carrier concentration [1-3]. A promising technique is to use DMS to inject spin-polarized carriers into nonmagnetic semiconductor, and it is very important that the DMS materials have room temperature ferromagnetic property for the practical applications. $\mathrm{ZnO}$ doped with transition metals is one of the most promising DMS candidates, as it was predicted to be ferromagnetic above room temperature $[1,4]$, and some room temperature ferromagnetic materials have been successfully synthesized by several groups [5-7]. To integrate the $\mathrm{ZnO}$ based DMSs into present electronics, it is reasoned that the combination of low dimensionality and room-temperature ferromagnetism in diluted magnetic oxides would generate new functional nanomaterials useful for future spintronics nanodevices. Some efforts have been focused on this kind of material, such as the fabrication of $\mathrm{Mn}$ doped $\mathrm{ZnO}$ nanorods arrays [8] and Co-doped $\mathrm{ZnO}$ nanoneedle arrays [9]. Recently, several codoped DMS materials have been reported with the expectation that codoping can lead to remarkable improvement in the properties of DMS $[10,11]$. Chakrabarti et al. reported that the saturation magnetic field can be enhanced by doping addition $2 \% \mathrm{Fe}$ in the $\mathrm{Mn}$-doped $\mathrm{ZnO}$ system [12]. Codoped $\mathrm{Mn}$ and $\mathrm{Fe}$ in $\mathrm{ZnO}$ nanostructures may contribute the local magnetic moments and enhancement of the charge carrier density. To the best of our knowledge, there was no research presented on $\mathrm{Mn}$ - and $\mathrm{Fe}$-codoped $\mathrm{ZnO}$ nanostructures. In this letter, magnetization above room temperature has been achieved in $(\mathrm{Mn}, \mathrm{Fe})$ codoped $\mathrm{ZnO}$ nanowires prepared by a chemical vapor deposition (CVD) route.

\section{Experiments}

The fabrication process of the chemical vapor deposition is similar to our previous reports [13]. A gold film with thickness of $2 \mathrm{~nm}$ acting as catalyst was sputtered on a cleaned silicon substrate. In a typical synthesis, $\mathrm{Zn}, \mathrm{Mn}$, and Fe powders were put in a small alumina boat to serve as source materials. Silicon wafer was placed above the source at a vertical distance of $5 \mathrm{~mm}$ with its gold side facing downwardly. Then, the alumina boat was transferred into 
the center of a horizontal alumina furnace. Argon with a flow rate of $30 \mathrm{sccm}$ (standard-state cubic centimeter per minute) was supplied as the carrier gas in the furnace during heating. When the temperature at the center of the furnace reached $810^{\circ} \mathrm{C}, 5 \mathrm{sccm}$ of oxygen was introduced. The furnace was held at $810^{\circ} \mathrm{C}$ for $2 \mathrm{~h}$ to synthesize the nanowires. During the whole growth process, the pressure of the system was maintained at atmospheric pressure without using pumping system. After the furnace was cooled down to room temperature, a yellowish film was observed on the silicon substrate. $\mathrm{ZnO}$ nanowires were synthesized at the similar condition only with $\mathrm{Zn}$ powder as the evaporation source.

X-ray diffraction (XRD) experiments were carried out with a X'pert MRD-Philips diffractometer using CuKa radiation. The micromorphology, structure, and composition of the products were studied using transmission electron microscopy (TEM, JEM-2010) and energy dispersive X-ray spectroscopy (EDXS). Elemental mapping was investigated by JEM-2100F microscope. Photoluminescence (PL) spectroscopy was performed at room-temperature, using a HeCd laser of $325 \mathrm{~nm}$ wavelength as the excitation source. Room-temperature unpolarized Raman spectra were excited with a $514.5 \mathrm{~nm} \mathrm{Ar}^{+}$laser, taken under backscattering geometry. Magnetization measurements were checked by means of a superconducting quantum interference device (SQUID, MPMS XL-7) magnetometer.

\section{Results and Discussion}

Figure 1 displays the indexed XRD pattern of the products, and the position and relative intensity of the diffraction peaks of both $(\mathrm{Mn}, \mathrm{Fe})$ codoped $\mathrm{ZnO}$ and pure $\mathrm{ZnO}$ nanowires are indexed to wurtzite $\mathrm{ZnO}$ structure. The $\mathrm{XRD}$ results of the $(\mathrm{Mn}, \mathrm{Fe})$ codoped $\mathrm{ZnO}$ nanowires demonstrate that the structure of the $\mathrm{ZnO}$ matrix is not changed by doping of $\mathrm{Mn}$ and Fe. The lattice constants measured from the XRD of the products are $a=0.3252 \mathrm{~nm}$ and $c=0.5211 \mathrm{~nm}$, which are a little larger than those of pure $\mathrm{ZnO}(a=0.3250 \mathrm{~nm}$ and $c=$ $0.5206 \mathrm{~nm})$. The ionic radius of $\mathrm{Zn}^{2+}, \mathrm{Mn}^{2+}, \mathrm{Mn}^{3+}, \mathrm{Fe}^{2+}$, and $\mathrm{Fe}^{3+}$ are $0.74,0.800 .66,0.74$, and $0.64 \mathrm{~nm}$, respectively. $\mathrm{Zn}$ ions replaced with $\mathrm{Fe}$ and $\mathrm{Mn}$ may result in the changing in lattice constants, and it also indicates that there is few $\mathrm{Mn}^{3+}$ and $\mathrm{Fe}^{3+}$ in the $(\mathrm{Mn}, \mathrm{Fe})$ coped $\mathrm{ZnO}$ nanowires, because the lattice constants increase slightly compared with those of pure $\mathrm{ZnO}$.

Figure 2(a) shows the typical TEM image of the (Mn,Fe) codoped $\mathrm{ZnO}$ nanowires, and it reveals that the mean diameter of the nanowires is around $65 \mathrm{~nm}$ with lengths up to several micrometers. High-resolution TEM (HRTEM) images show that the doped nanowires are of singlecrystalline nature, and the lattice fringe spacing of $0.247 \mathrm{~nm}$ corresponds to the $d$ value of (101) planes (Figure 2(b)). No any particle-like features were observed in the examined nanowires. The EDXS analysis reveals the existence of Mn and $\mathrm{Fe}$ ions in the $\mathrm{ZnO}$ samples, and the content of $\mathrm{Mn}$ and Fe are 6 at.\% and 2 at.\%, respectively. Elemental mapping was carried out to investigate the element distribution in the doped nanowires. The typical EDX elemental mapping

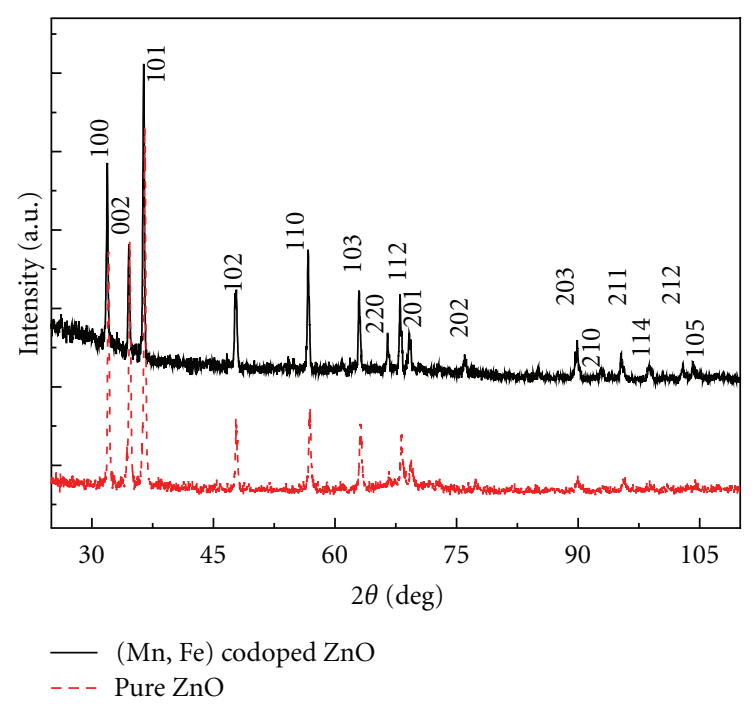

Figure 1: XRD pattern of the (Mn,Fe) codoped $\mathrm{ZnO}$ (solid line) and pure $\mathrm{ZnO}$ nanowires (dash line).

images of an individual $(\mathrm{Mn}, \mathrm{Fe})$ codoped $\mathrm{ZnO}$ nanowire were illustrated in Figure 3. These results show the shape of nanowire without any partial aggregation, which means that $\mathrm{Mn}$ and $\mathrm{Fe}$ distribute homogeneously in the nanowire instead of forming any oxide fine particles. Figure $3(d)$ shows that the profile of $\mathrm{O}$ is broader than those of the other elements, the reason is that $\mathrm{O}$ element was also absorbed by the supporting carbon film on the TEM grid and displaced in the profile.

The wurtzite $\mathrm{ZnO}$ structure belongs to the spaced group $C_{6 V}^{4}$, and the optical phonon irreducible representation is $2 A_{1}+2 B_{1}+2 E_{1}+2 E_{2}$. Both the $A_{1}$ and $E_{1}$ modes are polar and split into transverse optical (TO) and longitudinal optical (LO) phonons. Nonpolar $E_{2}$ modes are Raman active, while $B_{1}$ modes are Raman inactive. Their phonon frequencies of the Raman spectra in $\mathrm{ZnO}$ are $A_{1(\mathrm{TO})}=$ $380 \mathrm{~cm}^{-1}, A_{1(\mathrm{LO})}=574 \mathrm{~cm}^{-1}, E_{1(\mathrm{TO})}=407 \mathrm{~cm}^{-1}, E_{1(\mathrm{LO})}=$ $583 \mathrm{~cm}^{-1}, E_{2 \text { (High) }}=437 \mathrm{~cm}^{-1}$, and $E_{2(\text { Low })}=101 \mathrm{~cm}^{-1}$ [14], respectively. The frequency of $330 \mathrm{~cm}^{-1}$ is the secondorder spectrum arising from zone-boundary phonons 2$E_{2}(\mathrm{M})$ of $\mathrm{ZnO}$ [15]. The room temperature Raman spectra ranging from 200 to $850 \mathrm{~cm}^{-1}$ was presented in Figure 4. For the pure $\mathrm{ZnO}$ nanowires, the mode at $436.9 \mathrm{~cm}^{-1}$ with the strongest intensity is ascribed as $E_{2 \text { (high) phonon }}$ mode, which is the typical Raman peak of $\mathrm{ZnO}$ bulk. $E_{2 \text { (high) }}$ mode was usually used to understand the stressinduced phenomena in wurzite $\mathrm{ZnO}$ structures. As it is well known, an increase in the $E_{2 \text { (high) }}$ phonon frequency is ascribed to compressive stress, whereas a decrease in the $E_{2 \text { (high) }}$ phonon frequency is ascribed to tensile stress [16]. Compared with the frequency branch of $E_{2 \text { (high) }}$ phonon of $\mathrm{ZnO}\left(436.9 \mathrm{~cm}^{-1}\right)$, the line center position of $E_{2 \text { (high) }}$ phonon for the $(\mathrm{Mn}, \mathrm{Fe})$ codoped $\mathrm{ZnO}$ nanowires is observed at $434.9 \mathrm{~cm}^{-1}$, a Raman shift of $2.0 \mathrm{~cm}^{-1}$ had taken place, which indicates that a tensile stress was introduced in the nanowires because of the difference ionic radius between $\mathrm{Mn}, \mathrm{Fe}$, and 


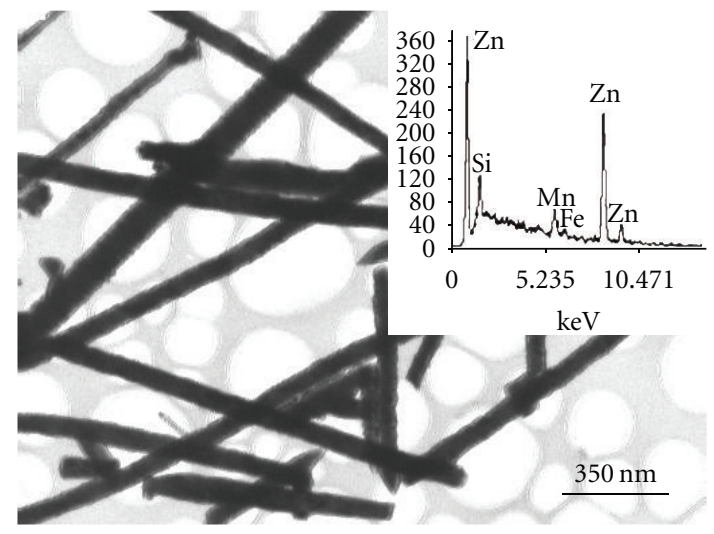

(a)

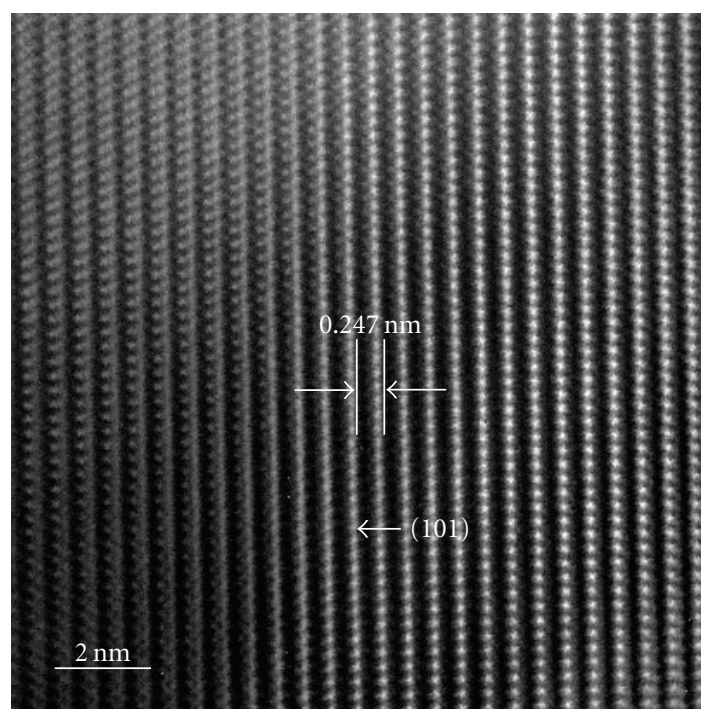

(b)

Figure 2: (a) Typical TEM image of the (Mn,Fe) codoped nanowires, and the inset is the EDS pattern. (b) HRTEM image of the (Mn,Fe) codoped $\mathrm{ZnO}$ nanowires, revealing the single crystalline.

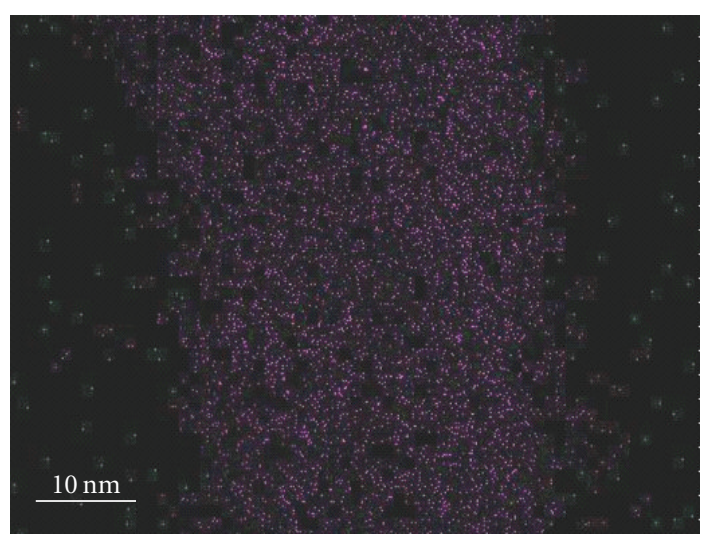

(a)

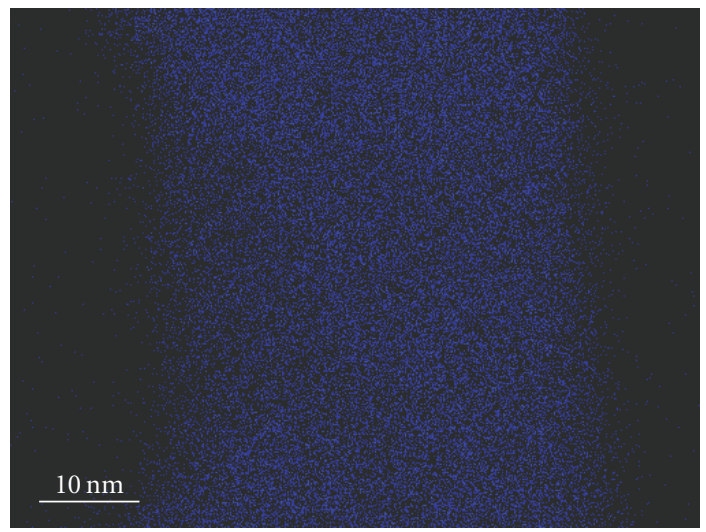

(c)

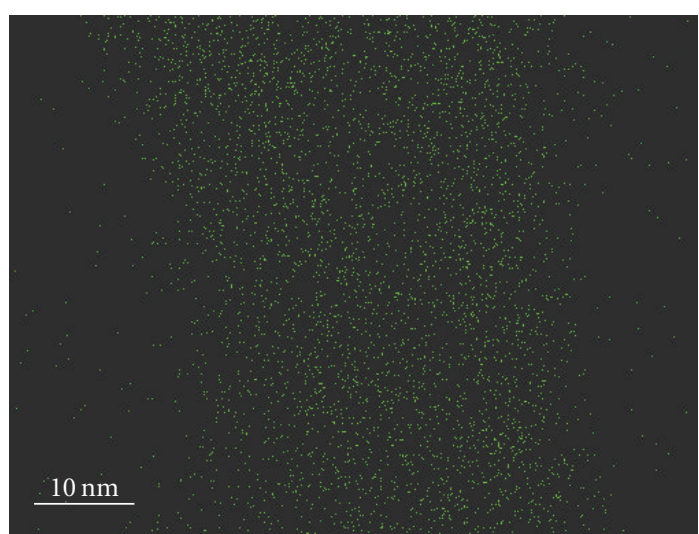

(b)

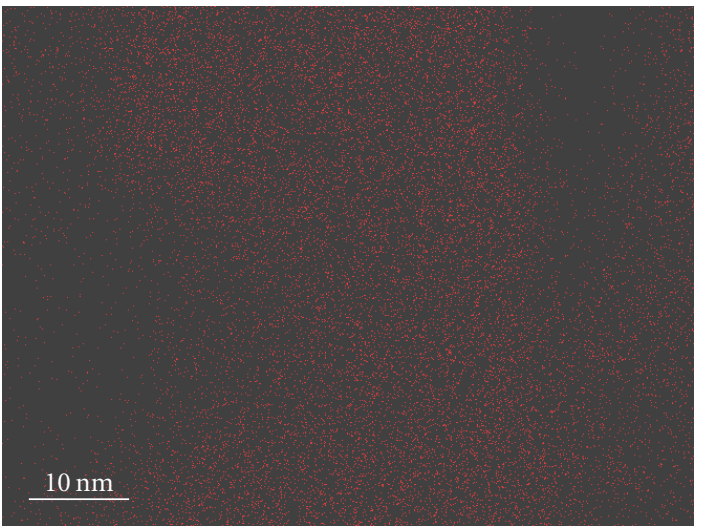

(d)

Figure 3: Elemental mapping images for the nanowire with Mn (a), Fe (b), Zn (c), and O (d). 


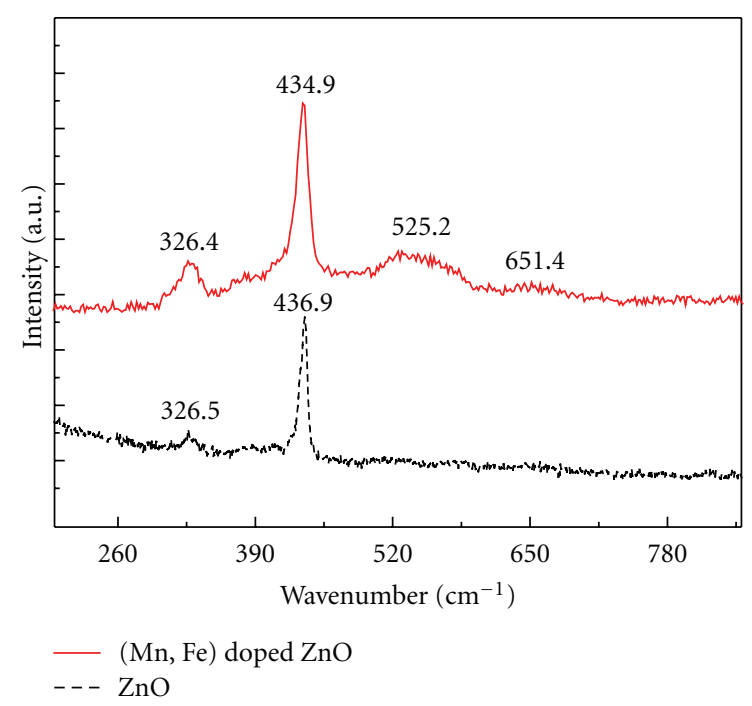

Figure 4: Raman spectra of the $(\mathrm{Mn}, \mathrm{Fe})$ codoped $\mathrm{ZnO}$ nanowires and pure $\mathrm{ZnO}$ nanowires.

$Z n$. The strongest intensity of $E_{2(\text { high })}$ phonon frequency for the $(\mathrm{Mn}, \mathrm{Fe})$ codoped $\mathrm{ZnO}$ nanowires also means that the wurtzite structure is preserved in spite of the inclusion of the $\mathrm{Mn}$ and $\mathrm{Fe}$ ions, which is consistent with the XRD results. The phonon mode centered at $326.5 \mathrm{~cm}^{-1}$ for $\mathrm{ZnO}$ and $326.4 \mathrm{~cm}^{-1}$ for $(\mathrm{Mn}, \mathrm{Fe})$ codoped $\mathrm{ZnO}$ are second-order spectra feature, which originates from the zone-boundary phonons of 2- $E_{2}(\mathrm{M})$ for $\mathrm{ZnO}$ [15]. In the Raman spectrum of the $(\mathrm{Mn}, \mathrm{Fe})$ codoped $\mathrm{ZnO}$ nanowires, there are two additional broad Raman bands at around $525.2 \mathrm{~cm}^{-1}$ and $651.4 \mathrm{~cm}^{-1}$, respectively. The vibration mode at $651.4 \mathrm{~cm}^{-1}$ was not presented in the $\mathrm{ZnO}$ films and single crystals, while it has been observed in $\mathrm{Mn}$ doped $\mathrm{ZnO}$ materials, where it was ascribed as local vibrational modes due to the intrinsic host-lattice defects [17]. In our experiments, when $\mathrm{Mn}$ and Fe atoms occupy the $\mathrm{Zn}$ sites, some new lattice defects are introduced or intrinsic host-lattice defects become activated due to the difference radius of $\mathrm{Mn}, \mathrm{Fe}$, and $\mathrm{Zn}$. So, we guess that the vibration mode at $651.4 \mathrm{~cm}^{-1}$ associated with the defects was induced by $\mathrm{Mn}$ and $\mathrm{Fe}$ substitution. The mode at $525.2 \mathrm{~cm}^{-1}$ was also detected in other Mn single and $\mathrm{Mn}$ codoped with other magnetic ions $\mathrm{ZnO}$ films and nanostructures prepared by other groups $[18,19]$, and this mode has been reported correlated with Mn-related local vibration. The above Raman analysis shows that only $\mathrm{ZnO}$ phase is obtained, and a tensile stress is introduced because of the doping of $\mathrm{Mn}$ and Fe.

Room temperature photoluminescence spectra of the assynthesized products were measured with excitation wavelength of $325 \mathrm{~nm}$. As shown in Figure 5, the PL spectrum of the $(\mathrm{Mn}, \mathrm{Fe})$ codoped $\mathrm{ZnO}$ nanowires is similar to many reported data of $\mathrm{ZnO}$. The luminescence band centered at $384 \mathrm{~nm}$ assigns to the ultraviolet (UV) excitonic emission, corresponding to the band emission of $\mathrm{ZnO}$. The green luminescence band was generally attributed to the single ionized oxygen vacancies [20]. Up to now, we have not seen

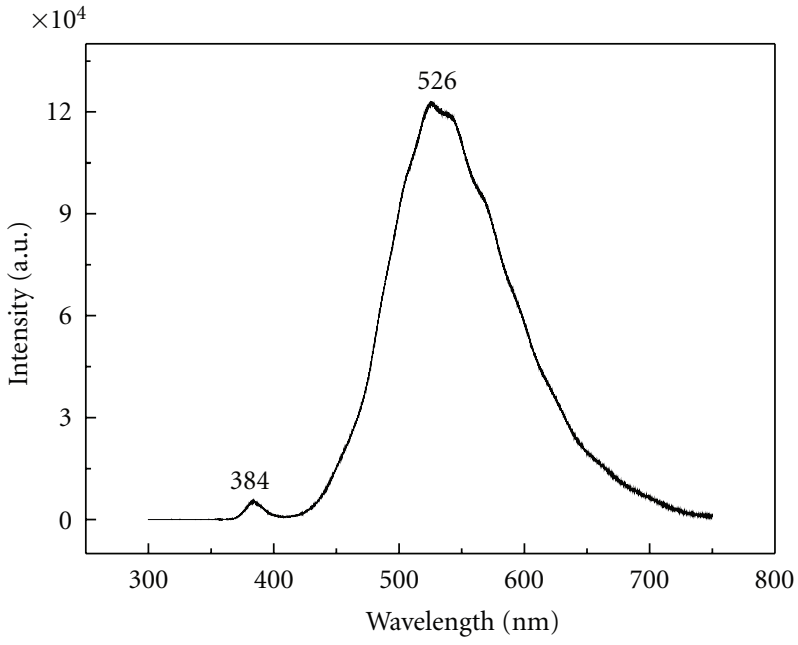

Figure 5: PL spectrum of the $(\mathrm{Mn}, \mathrm{Fe})$ codoped $\mathrm{ZnO}$ nanowires excited at room temperature.

any reports on the photoluminescence of $\mathrm{FeO}, \mathrm{Fe}_{2} \mathrm{O}_{3}, \mathrm{Fe}_{3} \mathrm{O}_{4}$, $\mathrm{Mn}_{2} \mathrm{O}_{3}$, and $\mathrm{Mn}_{3} \mathrm{O}_{4}$. A published report showed that $\mathrm{MnO}$ crystal shows the excitation spectra of the emission bands centered at $1.25 \mathrm{eV}(992 \mathrm{~nm})$ and $1.66 \mathrm{eV}(747 \mathrm{~nm})$ [21]. Figure 5 obviously shows that the green emission $(526 \mathrm{~nm})$ of the $(\mathrm{Mn}, \mathrm{Fe})$ codoped $\mathrm{ZnO}$ nanowires is not originated from $\mathrm{MnO}$. From above results, we can conclude that the strong green emission $(526 \mathrm{~nm})$ was merely due to defects in the doped $\mathrm{ZnO}$ nanowires instead of from secondary inclusions. The broad band with the strong intensity of the green emission indicates that there exist many oxygen vacancies in the doped materials. The doping of Mn and Fe may affect the emission of $\mathrm{ZnO}$. The high emission intensity of the near band emission only is observed in high crystal quality of $\mathrm{ZnO}$ [22]. If the material is of degraded quality, the exciton lifetime would be very short due to the additional scattering by defects, and the PL spectrum would be dominated by deep level emission. Mn and Fe dopants may introduce some defects and stress, which have been confined by the Raman spectra (Figure 4). The strong green emission in Figure 5 may result from the high quantity of oxygen vacancies and the defects originated from the dopants and the growth process.

The magnetic behavior of the doped materials is of critical importance for spintronics applications. Applied field-dependent magnetization $(M-H)$ measurements of the $(\mathrm{Mn}, \mathrm{Fe})$ codoped $\mathrm{ZnO}$ nanowires were performed at 5 and $300 \mathrm{~K}$, respectively. The diamagnetic response of the silicon substrate was subtracted from the magnetization plots. In Figure 6(a), the appearance of a well-defined loop with a coercive field of about 115 Oe signifies the $(\mathrm{Mn}, \mathrm{Fe})$ codoped $\mathrm{ZnO}$ nanowires being ferromagnetic at $5 \mathrm{~K}$. Figure $6(\mathrm{~b})$ shows the magnetic hysteresis curve measured at $300 \mathrm{~K}$. The saturated magnetization $M_{s}$ and coercive field $H_{c}$ are $0.4 \mathrm{emug}^{-1}$ and $35 \mathrm{Oe}$, respectively. Although the magnetization at $300 \mathrm{~K}$ is relatively weak compared with the value measured at $5 \mathrm{~K}$, the hysteresis loop was clearly observed at $300 \mathrm{~K}$, resulting from room-temperature ferromagnetic ordering in the $(\mathrm{Mn}, \mathrm{Fe})$ codoped $\mathrm{ZnO}$ nanowires. Recent 


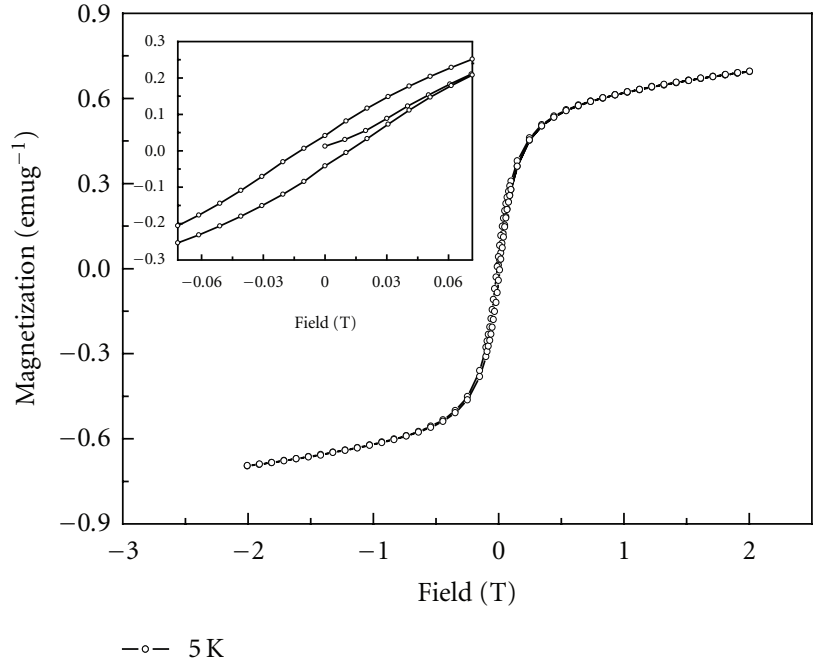

(a)

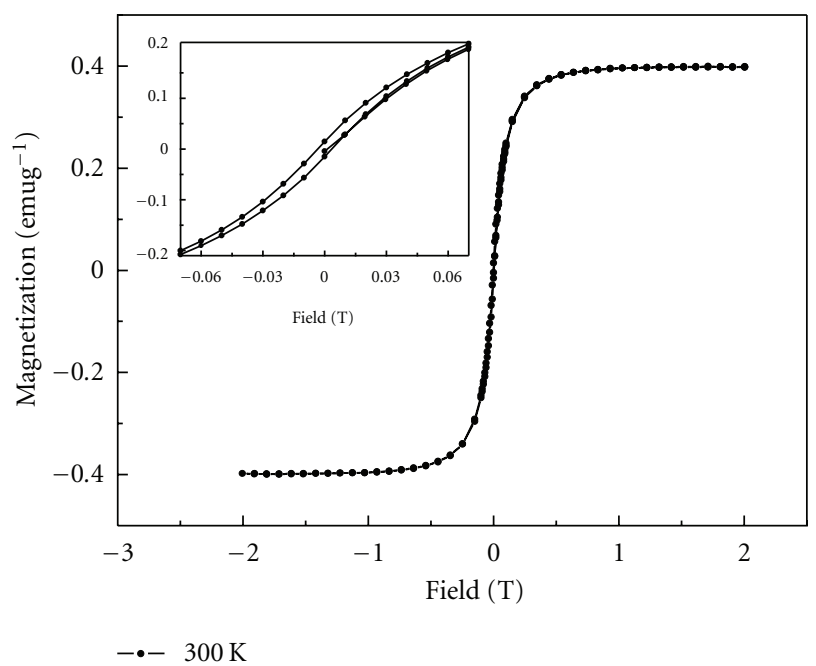

(b)

Figure 6: Hysteresis loops for the ( $\mathrm{Mn}, \mathrm{Fe})$ codoped $\mathrm{ZnO}$ nanowires measured at 5 (a) and $300 \mathrm{~K}(\mathrm{~b})$, and the corresponding insets show the enlarged parts of the $M-H$ curves.

works reported that the ferromagnetism in the $\mathrm{ZnO}$-based DMS controlled by the concentration of oxygen vacancies [23], and the enhancement of ferromagnetism was strongly correlated with the increase of oxygen vacancies in $\mathrm{ZnO}$ [24]. The PL measurements in our case demonstrate that there exist many oxygen vacancies in the doped materials. The room-temperature ferromagnetism of the $(\mathrm{Mn}, \mathrm{Fe})$ doped $\mathrm{ZnO}$ nanowires might originate from the super exchange interaction between nearest neighbor distance of magnetic ions (via oxygen vacancies). The role of $\mathrm{Mn}$ and Fe will be further investigated in the future.

\section{Conclusions}

This paper reported on the synthesis, characterization, and magnetic property of the $(\mathrm{Mn}, \mathrm{Fe})$ codoped $\mathrm{ZnO}$ nanowires through a chemical vapor deposition method. The XRD and Raman results show that the products are composed of pure wurtzite $\mathrm{ZnO}$ phase. HRTEM image indicates that the nanowires are of singe crystalline, and the elemental mapping profiles of the single nanowires show that the elements distribute homogeneously along the doped nanowires. Ferromagnetic behavior was obtained in the $(\mathrm{Mn}, \mathrm{Fe})$ codoped $\mathrm{ZnO}$ nanowires at low temperature as well as at room temperature. Our experimental results reveal that $\mathrm{Mn}$ and $\mathrm{Fe}$ incorporated into $\mathrm{ZnO}$ develop a room-temperature diluted magnetic semiconductor, which represents an important method for fabrication of transition metal-doped $\mathrm{ZnO}$ nanostructures with room-temperature ferromagnetic behavior.

\section{Acknowledgments}

This project is financially supported by Beijing Natural Science Foundation (no. 1092014), Open Project of Key Laboratory for Magnetism and Magnetic Materials of the Ministry of Education, Lanzhou University (LZUMMM2010002), and Metallurgy Foundation of University of Science and Technology Beijing. Y. Q. Chang is supported by Program for New Century Excellent Talents in University (no. NCET07-0065) and Beijing Novel Program.

\section{References}

[1] A. H. Macdonald, P. Schiffer, and N. Samarth, "Ferromagnetic semiconductors: moving beyond (Ga,Mn)As," Nature Materials, vol. 4, no. 3, pp. 195-202, 2005.

[2] J. B. Yi, H. Pan, J. Y. Lin et al., "Ferromagnetism in $\mathrm{ZnO}$ nanowires derived from electro-deposition on AAO template and subsequent oxidation," Advanced Materials, vol. 20, no. 6, pp. 1170-1174, 2008.

[3] N. H. Hong, J. Sakai, N. Poirot, and V. Brizé, "Roomtemperature ferromagnetism observed in undoped semiconducting and insulating oxide thin films," Physical Review B, vol. 73, no. 13, Article ID 132404, 4 pages, 2006.

[4] T. Dietl, H. Ohno, F. Matsukura, J. Cibert, and D. Ferrand, "Electric-field control of ferromagnetism," Science, vol. 287, no. 6815, pp. 1019-1022, 2000.

[5] P. Sharma, A. Gupta, K. V. Rao et al., "Ferromagnetism above room temperature in bulk and transparent thin films of Mndoped ZnO," Nature Materials, vol. 2, no. 10, pp. 673-677, 2003.

[6] T. S. Herng, D. C. Qi, T. Berlijn et al., "Room-temperature ferromagnetism of $\mathrm{Cu}$-doped $\mathrm{ZnO}$ films probed by soft X-ray magnetic circular dichroism," Physical Review Letters, vol. 105, no. 20, Article ID 207201, 2010.

[7] X. G. Xu, H. L. Yang, Y. Wu et al., "Intrinsic room temperature ferromagnetism in boron-doped ZnO," Applied Physics Letters, vol. 97, no. 23, Article ID 232502, 2010.

[8] H. L. Yan, X. L. Zhong, J. B. Wang et al., "Cathodoluminescence and room temperature ferromagnetism of Mn-doped $\mathrm{ZnO}$ nanorod arrays grown by chemical vapor deposition," Applied Physics Letters, vol. 90, no. 8, Article ID 082503, 2007. 
[9] L. R. Shah, W. Wang, H. Zhu et al., "Role of dopant, defect, and host oxide in the observed room temperature ferromagnetism: Co-ZnO versus Co-CeO ${ }_{2}$," Journal of Applied Physics, vol. 105, no. 7, Article ID 07C515, 3 pages, 2009.

[10] L. Q. Liu, B. Xiang, X. Z. Zhang, Y. Zhang, and D. P. Yu, "Synthesis and room temperature ferromagnetism of FeCocodoped ZnO nanowires," Applied Physics Letters, vol. 88, no. 6, Article ID 063104, 2006.

[11] D. Rubi, J. Fontcuberta, A. Calleja, L. Aragonès, X. G. Capdevila, and M. Segarra, "Reversible ferromagnetic switching in ZnO:(Co, Mn) powders," Physical Review B, vol. 75, no. 15, Article ID 155322, 2007.

[12] M. Chakrabarti, S. Dechoudhury, D. Sanyal, T. K. Roy, D. Bhowmick, and A. Chakrabarti, "Observation of room temperature ferromagnetism in Mn-Fe doped $\mathrm{ZnO}$," Journal of Physics D, vol. 41, no. 13, Article ID 135006, 2008.

[13] Y. Q. Chang, D. B. Wang, X. H. Luo et al., "Synthesis, optical, and magnetic properties of diluted magnetic semiconductor Zn1-xMnxO nanowires via vapor phase growth," Applied Physics Letters, vol. 83, no. 19, pp. 4020-4022, 2003.

[14] Z. C. Zhang, B. B. Huang, Y. Q. Yu, and D. L. Cui, "Electrical properties and Raman spectra of undoped and Al-doped $\mathrm{ZnO}$ thin films by metalorganic vapor phase epitaxy," Materials Science and Engineering B, vol. 86, no. 2, pp. 109-112, 2001.

[15] J. M. Calleja and M. Cardona, "Resonant Raman scattering in ZnO,” Physical Review B, vol. 16, no. 8, pp. 3753-3761, 1977.

[16] Y. Huang, M. Liu, Z. Li, Y. Zeng, and S. Liu, "Raman spectroscopy study of $\mathrm{ZnO}$-based ceramic films fabricated by novel sol-gel process," Materials Science and Engineering B, vol. 97, no. 2, pp. 111-116, 2003.

[17] L. W. Yang, X. L. Wu, G. S. Huang, T. Qiu, and Y. M. Yang, "In situ synthesis of Mn-doped $\mathrm{ZnO}$ multileg nanostructures and Mn-related Raman vibration," Journal of Applied Physics, vol. 97, no. 1, Article ID 014308, pp. 1-14308, 2005.

[18] C. L. Du, Z. B. Gu, M. H. Lu et al., "Raman spectroscopy of (Mn, Co)-codoped ZnO films," Journal of Applied Physics, vol. 99, no. 12, Article ID 123515, 2006.

[19] J. B. Wang, G. J. Huang, X. L. Zhong, L. Z. Sun, Y. C. Zhou, and E. H. Liu, "Raman scattering and high temperature ferromagnetism of Mn-doped $\mathrm{ZnO}$ nanoparticles," Applied Physics Letters, vol. 88, no. 25, Article ID 252502, 2006.

[20] X. L. Wu, G. G. Siu, C. L. Fu, and H. C. Ong, "Photouminescence and cathodoluminescence studies of stoichiometric and oxygen-deficient ZnO films," Applied Physics Letters, vol. 78, no. 16, pp. 2285-2287, 2001.

[21] S. Mochizuki, B. Piriou, and J. Dexpert-Ghys, "Spin-waveassisted photoluminescence in $\mathrm{MnO}$ crystals," Journal of Physics: Condensed Matter, vol. 2, no. 23, pp. 5225-5232, 1990.

[22] Y. Q. Chang, D. P. Yu, G. H. Li et al., "Photoluminescence characterization of nanocrystalline $\mathrm{ZnO}$ array," Chinese Physics Letters, vol. 21, no. 11, pp. 2301-2304, 2004.

[23] S. Ramachandran, J. Narayan, and J. T. Prater, "Effect of oxygen annealing on $\mathrm{Mn}$ doped $\mathrm{ZnO}$ diluted magnetic semiconductors," Applied Physics Letters, vol. 88, no. 24, Article ID 242503, 2006.

[24] H. S. Hsu, J. C. A. Huang, Y. H. Huang et al., "Evidence of oxygen vacancy enhanced room-temperature ferromagnetism in Co-doped ZnO," Applied Physics Letters, vol. 88, no. 24, Article ID 242507, 2006. 

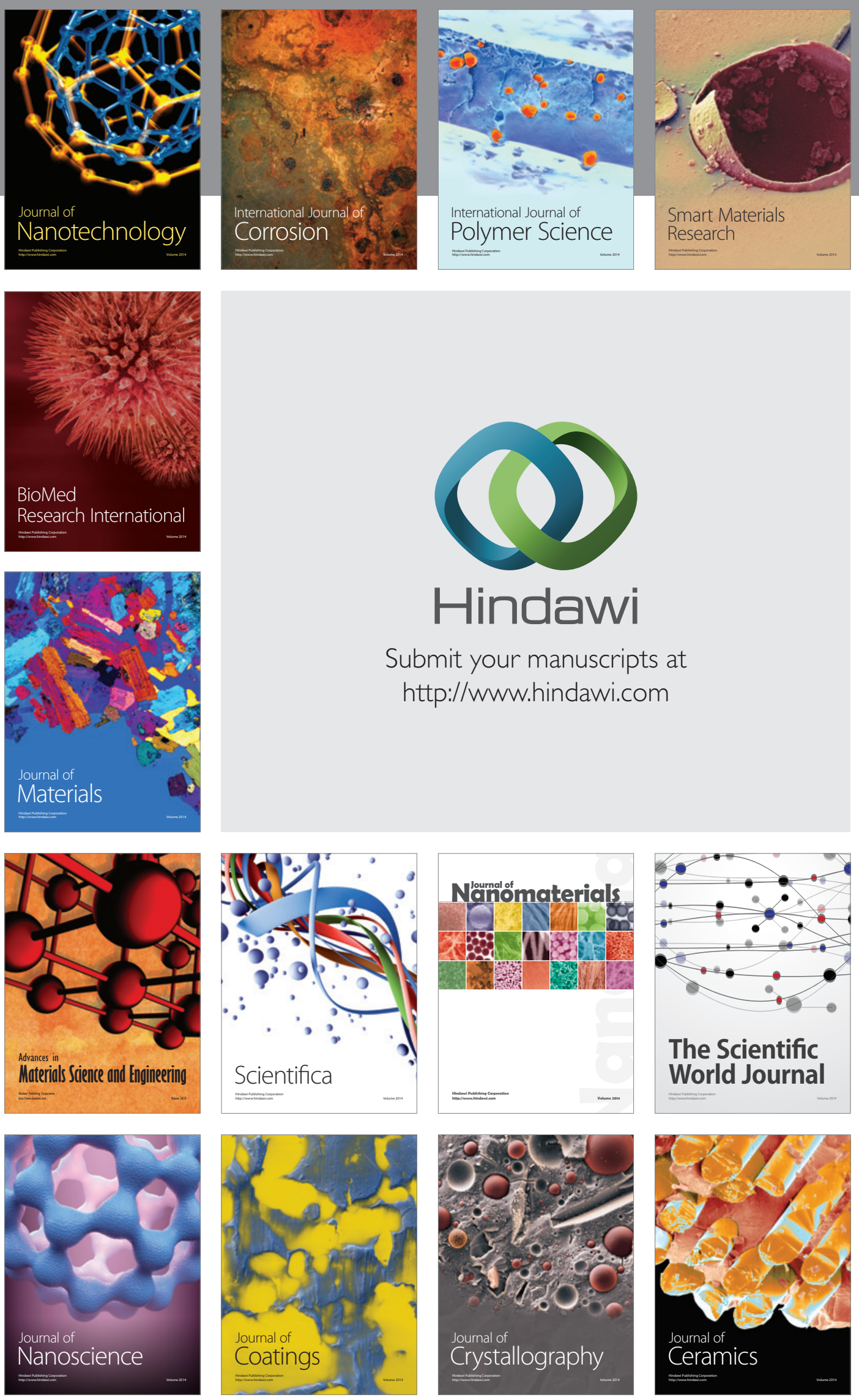

The Scientific World Journal

Submit your manuscripts at

http://www.hindawi.com

\section{World Journal}

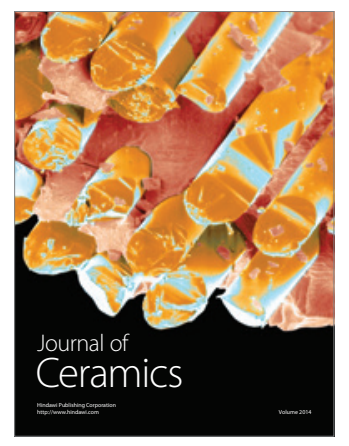

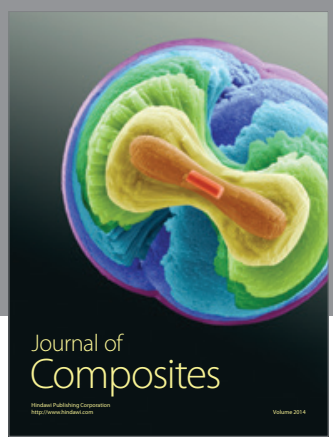
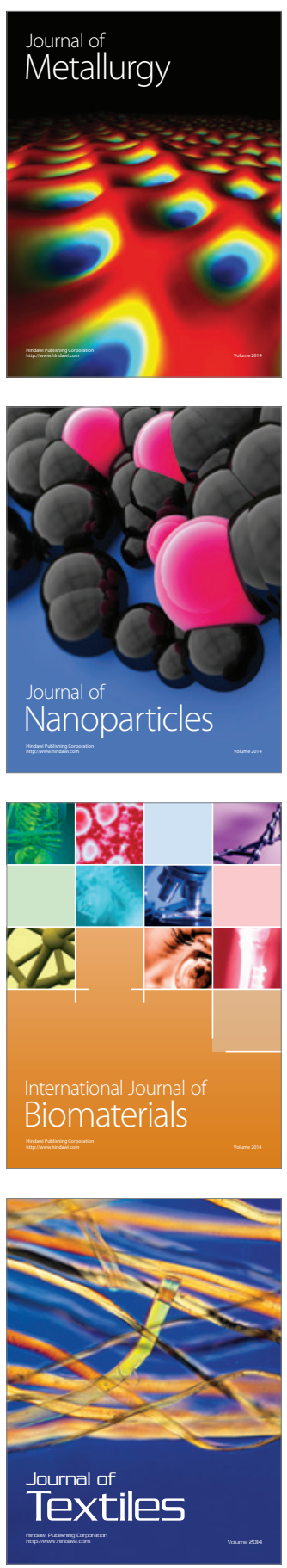